\title{
Production and Application of Monoclonal Antibodies to Human Selenoprotein P
}

\author{
Yoshiro Saito, ${ }^{a}$ Yasuko Watanabe, ${ }^{a}$ Eiji Saito, ${ }^{b}$ Tsutomu Honjoh,${ }^{c}$ and Kazuhiko Takahashi*, $a$ \\ ${ }^{a}$ Department of Hygienic Chemistry, Graduate School of Pharmaceutical Sciences, Hokkaido University, Kita 12, Nishi 6, Kita-ku, \\ Sapporo 060-0812, Japan, ${ }^{b}$ Second Department of Internal Medicine, Nihon University School of Medicine, 30-1 Ohyaguchi \\ Kamimachi, Itabashi-ku, Tokyo 173-0032, Japan, and 'Morinaga Institute of Biological Sciences, Shimosueyosi 2-1-1, Tsurumi-ku, \\ Yokohama 230-8504, Japan
}

(Received April 27, 2001; Accepted May 17, 2001)

\begin{abstract}
Selenoprotein $\mathrm{P}$ is a selenium-rich extracellular protein and is the major selenoprotein in plasma. Although the biological function of selenoprotein $\mathrm{P}$ has not been established, we have recently shown that selenoprotein $\mathrm{P}$ has phospholipid hydroperoxide glutathione peroxidase-like activity. To study the structure and function of selenoprotein $\mathrm{P}$, we produced monoclonal antibodies against human selenoprotein P. Immunization of rats with purified selenoprotein $\mathrm{P}$ was followed by hybridization, cloning, and the establishment of eleven hybridomas producing specific antibodies against human selenoprotein $\mathrm{P}$. With the addition of six kinds of insoluble rat anti-human selenoprotein P monoclonal antibodies to human plasma, the selenium concentration of the supernatant was decreased to $47 \%$ of the control. This suggests that selenoprotein P constituted 53\% of total plasma selenium. Western blot analysis of the immunoprecipitate from human plasma showed that the antibodies specifically bound to a $69 \mathrm{kDa}$ protein, representing selenoprotein P. Next, we developed an enzyme-linked immunosorbent assay for selenoprotein P using two monoclonal antibodies. The plasma concentration of selenoprotein P in 77 normal individuals was $5.3 \pm 1.1 \mu \mathrm{g} / \mathrm{ml}$. Because preferential depletion of selenoprotein P by low density lipoprotein (LDL)-apheresis has been reported, we next measured selenoprotein $\mathrm{P}$ concentration of plasma samples from patients before and after LDL-apheresis. We confirmed that the plasma concentration of selenoprotein $\mathrm{P}$ was decreased from 5.7 to $2.3 \mu \mathrm{g} / \mathrm{ml}$ by LDL-apheresis. This result shows that this assay provides a reliable means of measuring the content of selenoprotein $\mathrm{P}$ in plasma.
\end{abstract}

Key words — selenium, enzyme-linked immunosorbent assay, selenoprotein

\section{INTRODUCTION}

Selenium is an essential trace element and a deficiency of this element allows the development of a cardiomyopathy known as Keshan disease in China. ${ }^{1)}$ Epidemiological and animal studies also show that selenium deficiency predisposes to several pathological conditions, such as cancer, coronary heart disease and liver necrosis. ${ }^{2-5)}$ It was thought that selenium exerts its biological effects as a constituent of selenoproteins and that the pathological conditions associated with selenium deficiency are due to a decrease in selenoproteins. Extracellular glutathione peroxidase (eGPx) and selenoprotein $\mathrm{P}$ both exist as selenoprotein in human plasma. ${ }^{67)}$ eGPx, catalyzes the reduction of

\footnotetext{
*To whom correspondence should be addressed: Department of Hygienic Chemistry, Graduate School of Pharmaceutical Sciences, Hokkaido University, Kita 12, Nishi 6, Kita-ku, Sapporo 060-0812, Japan. Tel.: +81-11-706-3244; Fax: +81-11-706-4990; E-mail: kazu@pharm.hokudai.ac.jp
}

hydrogen peroxide and phospholipid hydroperoxide in the presence of glutathione, ${ }^{8,9)}$ and contains one selenium atom, in the form of selenocysteine, in the active site per subunit, which is encoded by the opal codon, UGA. ${ }^{10)}$ On the other hand, selenoprotein P is a selenium-rich protein. ${ }^{11,12)}$ The cDNA sequence suggests that selenoprotein $\mathrm{P}$ contains 10 selenocysteines encoded by UGA stop codons in the open reading frame of its mRNA. ${ }^{13,14)}$ Several lines of evidence in vivo also suggest that selenoprotein $\mathrm{P}$ is a free radical scavenger. ${ }^{15,16)} \mathrm{Re}$ cently, we demonstrated that selenoprotein $\mathrm{P}$ can reduce phospholipid hydroperoxide in the presence of glutathione. ${ }^{17)}$

In this paper, we report the production of antibodies against human selenoprotein $\mathrm{P}$ by using a method of preparing rat-monoclonal antibody-producing hybridomas. By utilizing these antibodies, we analyzed the selenium content and form of selenoprotein $\mathrm{P}$ in human plasma, developed a reliable enzyme-linked immunosorbent assay (ELISA) 
for human selenoprotein $\mathrm{P}$, and finally applied it to plasma samples from normal individuals and patients treated by LDL-apheresis.

\section{MATERIALS AND METHODS}

\section{Preparation of Monoclonal Antibody against} Selenoprotein $\mathbf{P}-$ A technique for preparing hybridomas producing rat monoclonal antibodies was used in this study. ${ }^{18,19)}$ Human selenoprotein $P$ was purified as described previously. ${ }^{17)}$ Eight-week-old female WKY/NCrj rats were injected via their hind footpads with an emulsion containing purified human selenoprotein P and Freund's complete adjuvant. The animals were sacrificed $2-5$ weeks after initial immunization. The cells from enlarged medial iliac lymph nodes were used for cell fusion, followed by hybridization, cloning, and the establishment of hybridomas. Screening for the production of anti-human selenoprotein $\mathrm{P}$ antibodies was done by solid-phase ELISA. The class and subclass of rat monoclonal antibodies was determined using a Rat MonoAb ID/SP Kit (Zymed Laboratories Inc., South San Francisco, CA, U.S.A.). Monoclonal antibodies were purified from culture media in which hybridomas were growing, using $40 \%$ saturated ammonium sulfate precipitation and DE-52 column chromatography (Whatman Int., Kent, U.K.).

\section{Immunoprecipitation and Immunoblotting of} Selenoprotein $\mathbf{P}-$ Six monoclonal antibodies (BD1, BD3, BF2, AE2, AH5 and AA3) were used for this study. The six antibodies were coupled to Sepharose 4B (Amersham Pharmacia Biotech, Uppsala, Sweden) by using cyanogen bromide. ${ }^{20)}$ After the addition of varying amounts of the six antibody-conjugated Sepharose 4B to human plasma, the selenium content of the supernatant was measured as described previously. ${ }^{17)}$ The six antibodyconjugated Sepharose 4B was applied to plasma and incubated for $1 \mathrm{hr}$ at $4^{\circ} \mathrm{C}$. The column was washed by phosphate buffered saline (PBS) and eluted with PBS containing $0.8 \%$ SDS, $0.004 \%$ bromophenol blue, $0.004 \%$ malachite green and $4 \%$ glycerol. Samples were subjected to SDS-polyacrylamide gel electrophoresis in slab gels (12.5\% gel) under nonreducing or reducing conditions, according to the method of Laemmli. ${ }^{21)}$ After electrophoresis, proteins in the gel were electroblotted onto a polyvinylidene difluoride membrane (Millipore Co., Bedford, MA, U.S.A.). Proteins in the membrane was detected by six horseradish peroxidase (HRP)-conjugated mono- clonal antibodies, which were conjugated with HRP according to the methods of Nakane et al. ${ }^{22)}$ HRPlabeled bands were detected using an enhanced chemiluminescence kit (Amersham Pharmacia Biotech, Uppsala, Sweden).

The Sandwich ELISA Procedure —— Ninety-sixwell microtiter plates were coated for $18 \mathrm{hr}$ at $4^{\circ} \mathrm{C}$ with $100 \mu \mathrm{l}$ of rat anti-human selenoprotein $\mathrm{P}$ monoclonal antibody BD1 $(5 \mu \mathrm{g} / \mathrm{ml})$ in $0.05 \mathrm{M}$ sodium bicarbonate buffer, $\mathrm{pH}$ 9.6. The wells were washed three times with PBS containing $0.05 \%$ Tween 20 , and incubated at $37^{\circ} \mathrm{C}$ with $150 \mu \mathrm{l}$ of Block Ace for $1 \mathrm{hr}$. After washing the wells three times, $50 \mu \mathrm{l}$ of selenoprotein P standard or plasma sample (diluted with PBS, containing $0.05 \%$ Tween 20 and $0.1 \%$ bovine serum albumin, PBS-Tween-BSA) was added to each well, and incubated at $37^{\circ} \mathrm{C}$ for $1 \mathrm{hr}$. After washing the wells three times, $50 \mu$ l of HRP-conjugated rat anti-human selenoprotein $\mathrm{P}$ monoclonal antibody AH5 $(20 \mu \mathrm{g} / \mathrm{ml})$ was added, and incubated at $37^{\circ} \mathrm{C}$ for $1 \mathrm{hr}$. Finally, the plates were washed three times, and dried by shaking. Fifty microliters of $\mathrm{TMB}^{+}$(DAKO Co., Carpinteria, CA, U.S.A.) was added to each well, and the enzyme-substrate reaction was allowed to proceed for $30 \mathrm{~min}$ in the dark. The reactions were stopped by the addition of $50 \mu \mathrm{l}$ of $1 \mathrm{M}$ sulphuric acid to each well. The absorbances were read at $450 \mathrm{~nm}$ in a Dual Wavelength Flying Spot Scanning Densitometer CS-9300 PC. Wells receiving all reagents apart from serum sample were used as blanks.

Blood Samples and Biochemical Analysis of Volunteers and Patients — Seventy-three healthy adult volunteers (50 males and 23 females, aged $54.0 \pm 7.2$ years) participated in this study. The patients treated by LDL-apheresis all had familial hypercholesterolemia, and five of them had severe coronary artery disease. Diagnoses were based on pedigree analysis and Achilles tendon thickness. All patients received oral drug therapy first, and those for whom this therapy was unsuccessful received LDL-apheresis. They were treated LDL-apheresis at 2-week intervals, and 3 to 4 liters of plasma was treated at each apheresis. Pre-treatment blood was drawn from the vein of the patients at the first apheresis and the post-treatment blood samples were obtained at an end of apheresis. The blood was sampled into glass tubes containing EDTA $(1 \mathrm{mg} /$ $\mathrm{ml}$ blood), immediately separated to plasma by centrifugation for $15 \mathrm{~min}$ at $1700 \mathrm{~g}$, and each plasma sample was kept at $-80^{\circ} \mathrm{C}$ until measurement. Selenium concentration was determined according to the 
Table 1. Properties of Rat Anti-Human SeP Monoclonal Antibodies

\begin{tabular}{cccc}
\hline \hline & subclass & L chain & immunoblotting \\
\hline AA3 & IgG1 & $\kappa$ & ++ \\
AB1 & $\operatorname{IgG1}$ & $\kappa$ & - \\
AE2 & $\operatorname{IgG1}$ & $\kappa$ & + \\
AH5 & $\operatorname{IgG1}$ & $\kappa$ & ++ \\
BD1 & $\operatorname{IgG2a}$ & $\kappa$ & +++ \\
BD3 & $\operatorname{IgG2a}$ & $\kappa$ & ++ \\
BF2 & $\operatorname{IgG1}$ & $\kappa$ & + \\
DH6 & $\operatorname{IgG1}$ & $\kappa$ & - \\
DH7 & $\operatorname{IgG} 1$ & $\kappa$ & - \\
DH9 & $\operatorname{IgG} 1$ & $\kappa$ & - \\
DC12 & $\operatorname{IgG1}$ & $\kappa$ & - \\
\hline
\end{tabular}

fluorometric method of Bayfield and Romalis. ${ }^{23)}$ Total plasma cholesterol was measured using an enzymatic method. LDL cholesterol concentration was measured directly using a homogenous method (Daiichi Chemical Inc., Tokyo, Japan).

\section{RESULTS}

Using purified selenoprotein $\mathrm{P}$ as an antigen, 11 hybridomas were obtained by using a method for preparing hybridomas producing rat monoclonal antibodies. The properties of these antibodies are summarized in Table 1. These monoclonal antibodies can be used for ELISA, and six of them can be used for immunoblot.

Figure 1A shows the immunoprecipitation of selenoprotein $\mathrm{P}$ in human plasma. Plasma Se was decreased in a dose-dependent manner. The decrease reached a constant at $47 \%$ of the control. Next, we conducted immunoblot analysis (Fig. 1B). A major $69 \mathrm{kDa}$ band could be detected on the immunoblot, while a weaker stained band with a higher molecular mass could also detected under non-reducing conditions, but not under reducing conditions (data not shown).

We developed an ELISA for selenoprotein P. Selenoprotein $\mathrm{P}$ purified from human plasma was serially diluted and introduced into the wells of microtiter plates coated with the anti-selenoprotein P monoclonal antibody, BD1. A typical standard curve is shown in Fig. 2. To examine the possibility of assaying selenoprotein $\mathrm{P}$ in plasma, the plasma was diluted 10- to 1000 -fold. The relationship was linear for immunoreactive selenoprotein $\mathrm{P}$ at a dilution of over 30- to 200-fold (data not shown). Accordingly, plasma samples were routinely diluted 100-fold with PBS-Tween-BSA before use. We have found this assay to be highly reproducible when identical samples are compared in either intra-assay or inter-assay, with the relative standard deviations within triplicate determinations were $4.0 \%$ and $7.7 \%$, respectively. The plasma concentration of selenium in 73 normal individuals was $116 \pm 17 \mathrm{ng} / \mathrm{ml}$ and that of selenoprotein P was $5.3 \pm 1.1 \mu \mathrm{g} / \mathrm{ml}$. There was
A

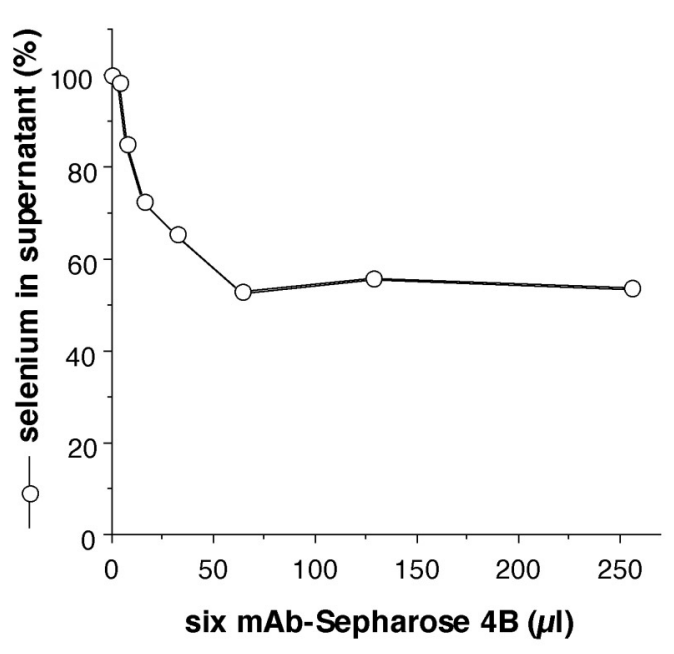

B

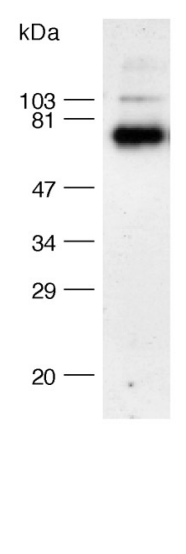

Fig. 1. Immunoprecipitation and Immunoblot Analysis of Selenoprotein P in Human Plasma

A, After the addition of varying amounts of the six antibody-conjugated Sepharose $4 \mathrm{~B}$ to human plasma, the selenium content of the supernatant was measured as described "Material and Methods." B, After the addition of six monoclonal antibody-conjugated-Sepharose 4B to human plasma, the immunoprecipitate was subjected to immunoblot analysis. Molecular mass standard locations are shown on the left. 


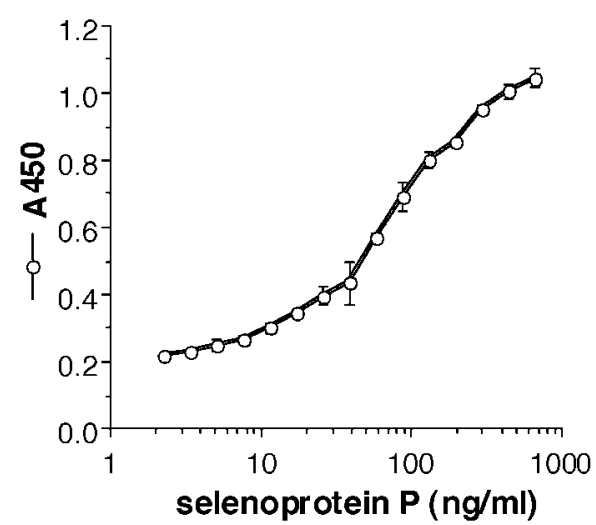

Fig. 2. Standard Curve of ELISA for Human Selenoprotein $P$ The values represent the means \pm SEM for triplicate.

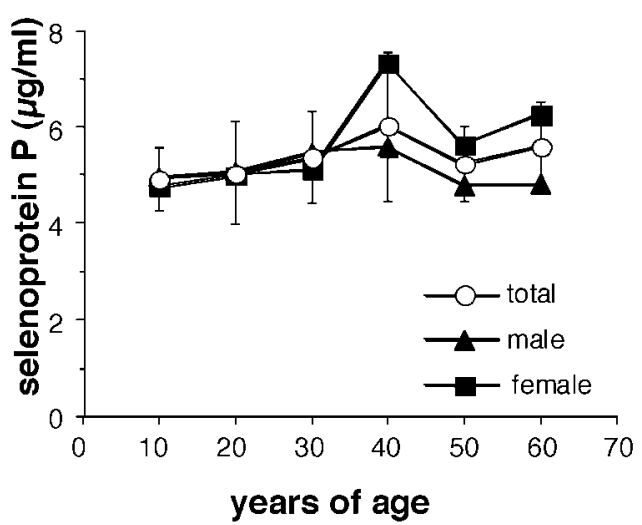

Fig. 3. The Plasma Concentration of Human Selenoprotein $P$ of Healthy Individuals

no correlation between selenoprotein $\mathrm{P}$ and selenium in healthy subjects (data not shown). Selenoprotein $P$ concentrations for each age group and gender are shown in Fig. 3, and no significant differences were observed between age and gender.

Because the preferential depletion of selenoprotein $\mathrm{P}$ by LDL-apheresis has been reported ${ }^{24)}$ we measured selenoprotein $\mathrm{P}$ concentra- tion of plasma samples from patients before and after LDL-apheresis using our assay system. We found that total cholesterol and LDL cholesterol were decreased to $49 \%$ and $38 \%$, respectively, after treatment. Significant decreases were also observed in plasma selenium and selenoprotein $\mathrm{P}$ concentrations after treatment (Table 2).

\section{DISCUSSION}

Selenoprotein $\mathrm{P}$ has been demonstrated to contain more than one selenium atom per polypeptide chain. ${ }^{25)}$ Although the biological function of selenoprotein $\mathrm{P}$ has not been established, we have recently shown that selenoprotein $\mathrm{P}$ has phospholipid hydroperoxide glutathione peroxidase-like activity. ${ }^{17)}$ For further study of the structure and function of selenoprotein $\mathrm{P}$, we raised monoclonal antibodies against selenoprotein $\mathrm{P}$. By the addition of six monoclonal antibody-conjugated Sepharose 4B to plasma, plasma selenium concentration was decreased to $47 \%$ of the control (Fig. 1A). This suggests that $53 \%$ of plasma selenium was associated with selenoprotein $\mathrm{P}$, and this result is in close agreement with previously reported values. ${ }^{7}$ Immunoblot analysis of the immunoprecipitate gave only one major $69 \mathrm{kDa}$ band (Fig. 1B), suggesting that selenoprotein $\mathrm{P}$ is present in one major form. Selenoprotein $\mathrm{P}$ in human plasma is reported to be present in two isoforms. ${ }^{7,26)}$ It is probable that a lowmolecular-weight selenoprotein $\mathrm{P}$ was produced by plasma protease in the course of the purification procedure.

It has been reported that insufficient plasma selenium levels are associated with a decreased survival rate of human immunodeficiency virus (HIV)infected patients, increased rate of cancer incidence and atherosclerosis. ${ }^{2,3,27)}$ However, it is not known which selenoprotein is responsible for this effect.

Table 2. Plasma Selenium and Selenoprotein Concentrations before and after Treatment of Hypercholesterolaemic Patients by Apheresis

\begin{tabular}{cccc}
\hline \hline & $\begin{array}{c}\text { Hypercholesterolaemic } \\
\text { patients before LDL- } \\
\text { apheresis }(n=7)\end{array}$ & $\begin{array}{c}\text { Hypercholesterolaemic } \\
\text { patients after LDL- } \\
\text { apheresis }(n=7)\end{array}$ & $\begin{array}{c}\text { Significance } \\
\text { (before and after } \\
\text { LDL-apheresis) }\end{array}$ \\
\hline total cholesterol $(\mathrm{mmol} / \mathrm{l})$ & $206(29)$ & $100(16)$ & $p<0.001$ \\
LDL cholesterol $(\mathrm{mmol} / \mathrm{l})$ & $144(22)$ & $54(15)$ & $p<0.001$ \\
$\mathrm{Se}(\mathrm{ng} / \mathrm{ml})$ & $121(13)$ & $85(15)$ & $p<0.001$ \\
$\mathrm{SeP}(\mu \mathrm{g} / \mathrm{ml})$ & $5.7(1.1)$ & $2.3(1.3)$ & $p<0.001$ \\
$\mathrm{eGPx}(\mathrm{mU} / \mathrm{ml})$ & $402(43)$ & $368(37)$ & - \\
\hline
\end{tabular}


To understand the relationship between these diseases and selenoprotein P, we developed an ELISA for selenoprotein P by using BD1 and AH5. First, we applied this ELISA to plasma samples from normal individuals (Table 1). There was no correlation between selenoprotein $\mathrm{P}$ and selenium concentrations. Further, no significant differences were detected between age and gender. This result was in agreement with that of a previous report. ${ }^{28)}$

The relationship between total cholesterol and LDL cholesterol levels and incidence of coronary artery disease (CAD) is well established. ${ }^{29,30)}$ Primary and secondary prevention trials have shown that lipid-lowering therapy results in a reduced progression of atherosclerosis. ${ }^{31-33)}$ LDL apheresis, the direct removal of plasma LDL from circulating blood by using an extracorporeal circulation technique, is thought to be the most intensive treatment for familial hypercholesterolemia $(\mathrm{FH})$ with $\mathrm{CAD}$ when plasma LDL levels can not be sufficiently lowered by drugs. Combined treatment with LDL-apheresis and cholesterol lowering drugs for patients at high risk for cardiovascular events arrests further progression of $\mathrm{CAD}$, and induces functional improvement of the coronary blood flow. ${ }^{34)}$ On the other hand, it has been reported that there is a significant inverse correlation between the plasma selenium level and severity of coronary atherosclerosis or common carotid atherosclerosis. ${ }^{3,4)}$ As selenoprotein $P$ reduces lipid peroxide, ${ }^{17)}$ it might act as an anti-atherogenic enzyme to prevent the formation of oxidized LDL. Seven FH subjects in this study were treated with LDL-apheresis at 2-week intervals for several years. The ELISA developed by us confirmed that selenoprotein $\mathrm{P}$ levels were reduced by LDLapheresis treatment (Table 2). It is conceivable that apheresis may result in a decrease of plasma selenium and selenoprotein $\mathrm{P}$ concentrations each time. In most cases, the selenoprotein $P$ concentration of patients before treatment was equal to that of normal individuals. Therefore, a lower selenoprotein $P$ level is a possible risk factor for atherosclerotic disease. If this is the case, it is important to measure the selenoprotein $\mathrm{P}$ level of patients treated with LDL-apheresis in order to determine whether selenium supplementation is necessary.

The newly developed ELISA provides an easier and more reliable means of measuring the selenoprotein $\mathrm{P}$ content of plasma, than previously reported assays for selenoprotein $\mathrm{P}$, such as radioimmunoassay ${ }^{24,25)}$ or chromatographic assay. ${ }^{35)}$
Acknowledgements This work was supported in part by a Grant-in-Aids for Scientific Research from the Ministry of Education, Culture, Sports, Sciences and Technology, of Japan. We also thank the Hokkaido Red Cross Blood Center for providing human plasma.

\section{REFERENCES}

1) Chen, X., Yang, G., Chen, J., Chen, X., Wen, Z. and Ge, K. (1980) Studies on the relations of selenium and Keshan disease. Biol. Trace Elem. Res., 2, 91107.

2) Clark, L. C., Combs, G. F., Jr., Turnbull, B. W., Slate, E. H., Chalker, D. K., Chow, J., Davis, L. S., Glover, R. A., Graham, G. F., Gross, E. G., Krongrad, A., Lesher, J. L., Jr., Park, H. K., Sanders, B. B., Jr., Smith, C. L. and Taylor, J. R. (1996) Effects of selenium supplementation for cancer prevention in patients with carcinoma of the skin.J.Am. Med. Assoc., 276, 1957-1963.

3) Salonen, J. T., Salonen, R., Seppanen, K., Kantola, M., Suntioinen, S. and Korpela, H. (1991) Interactions of serum copper, selenium, and low density lipoprotein cholesterol in atherogenesis. Br. Med.J., 302, 756-760.

4) Suadicani, P., Hein, H. O. and Gyntelberg, F. (1992) Serum selenium concentration and risk of ischaemic heart disease in a prospective cohort study of 3000 males. Atherosclerosis, 96, 33-42.

5) Burk, R. F., Lawrence, R. A. and Lane, J. M. (1980) Liver necrosis and lipid peroxidation in the rat as the result of paraquat and diquat administration. Effect of selenium deficiency. J. Clin. Invest. $\mathbf{6 5}$, 1024-1031.

6) Takahashi, K. and Cohen, H. J. (1986) Seleniumdependent glutathione peroxidase protein and activity: immunological investigations on cellular and plasma enzymes. Blood, 68, 640-645.

7) Akesson, B., Bellew, T. and Burk, R. F. (1994) Purification of selenoprotein $\mathrm{P}$ from human plasma. Biochim. Biophys. Acta, 1204, 243-249.

8) Takahashi, K., Avissar, N., Whitin, J. and Cohen, H. (1987) Purification and characterization of human plasma glutathione peroxidase: a selenoglycoprotein distinct from the known cellular enzyme. Arch. Biochem. Biophys., 256, 677-686.

9) Yamamoto, Y. and Takahashi, K. (1993) Glutathione peroxidase isolated from plasma reduces phospholipid hydroperoxides. Arch. Biochem. Biophys., 305, 541-545.

10) Takahashi, K., Akasaka, M., Yamamoto, Y., Kobayashi, C., Mizoguchi, J. and Koyama, J. (1990) 
Primary structure of human plasma glutathione peroxidase deduced from cDNA sequences. J. Biochem. (Tokyo), 108, 145-148.

11) Burk, R. F. and Hill, K. E. (1994) Selenoprotein P. A selenium-rich extracellular glycoprotein. J. Nutr., 124, 1891-1897.

12) Saito, Y. and Takahashi, K. (2000) Selenoprotein P: its structure and function. J. Health Sci. 46, 409413.

13) Hill, K. E., Lloyd, R. S., Yang, J. G., Read, R. and Burk, R. F. (1991) The cDNA for rat selenoprotein $\mathrm{P}$ contains 10 TGA codons in the open reading frame. J. Biol. Chem., 266, 10050-10053.

14) Hill, K. E., Lloyd, R. S. and Burk, R. F. (1993) Conserved nucleotide sequences in the open reading frame and 3' untranslated region of selenoprotein $\mathrm{P}$ mRNA. Proc. Natl. Acad. Sci. U.S.A., 90, 537-541.

15) Burk, R. F., Hill, K. E., Awad, J. A., Morrow, J. D., Kato, T., Cockell, K. A. and Lyons, P. R. (1995) Pathogenesis of diquat-induced liver necrosis in selenium-deficient rats - Assessment of the roles of lipid peroxidation and selenoprotein P. Hepatology, 21, 561-569.

16) Burk, R. F., Hill, K. E., Awad, J. A., Morrow, J. D. and Lyons, P. R. (1995) Liver and Kidney Necrosis In Selenium-Deficient Rats Depleted Of Glutathione. Lab. Invest., 72, 723-730.

17) Saito, Y., Hayashi, T., Tanaka, A., Watanabe, Y., Suzuki, M., Saito, E. and Takahashi, K. (1999) Selenoprotein P in Human Plasma as an Extracellular Phospholipid Hydroperoxide Glutathione Peroxidase. Isolation and enzymatic characterization of human selenoprotein P. J. Biol. Chem., 274, 2866 2871.

18) Kishiro, Y., Kagawa, M., Naito, I. and Sado, Y. (1995) A novel method of preparing rat-monoclonal antibody-producing hybridomas by using rat medial iliac lymph node cells. Cell Stru. Func., 20, 151156.

19) Sado, Y., Kagawa, M., Kishiro, Y., Sugihara, K., Naito, I., Seyer, J. M., Sugimoto, M., Oohashi, T. and Ninomiya, Y. (1995) Establishment by the rat lymph node method of epitope-defined monoclonal antibodies recognizing the six different $\alpha$ chains of human type IV collagen. Histochem. Cell Biol., 104, 267-275.

20) Cuatrecasas, P. (1970) Protein purification by affinity chromatography. Derivatizations of agarose and polyacrylamide beads. J. Biol. Chem., 245, 30593065.

21) Laemmli, U. K. (1970) Cleavage of structural proteins during the assembly of the head of bacteriophage T4. Nature (London), 227, 680-685.

22) Nakane, P. K. and Kawaoi, A. (1974) Peroxidaselabeled antibody. A new method of conjugation. $J$.
Histochem. Cytochem. 22, 1084-1091.

23) Bayfield, R. F., and Romalis, L. F. (1985) pH Control in the fluorometric assay for selenium with 2,3diaminonaphthalene. Anal. Biochem., 144, 569-576.

24) Persson-Moschos, M., Bonnefont-Rousselot, D., Assogba, U., Bruckert, E., Jaudon, M. C., Delattre, J. and Akesson, B. (1995) Preferential depletion of selenoprotein $\mathrm{P}$ in hypercholesterolaemic patients treated by LDL-apheresis. Clin. Chim. Acta, 240, 209-212.

25) Hill, K. E., Xia, Y., Akesson, B., Boeglin, M. E. and Burk, R. F. (1996) Selenoprotein P concentration in plasma is an index of selenium status in seleniumdeficient and selenium-supplemented Chinese subjects. J. Nutr., 126, 138-145.

26) Read, R., Bellew, T., Yang, J. G., Hill, K. E., Palmer, I. S. and Burk, R. F. (1990) Selenium and amino acid composition of selenoprotein $\mathrm{P}$, the major selenoprotein in rat serum. J. Biol. Chem., 265, 17899-17905.

27) Mostert, V., Lombeck, I. and Abel, J. (1998) A novel method for the purification of selenoprotein $\mathrm{P}$ from human plasma. Arch. Biochem. Biophys., 357, 326330 .

28) Baum, M. K., Shor-Posner, G., Lai, S., Zhang, G., Lai, H., Fletcher, M. A., Sauberlich, H. and Page, J. B. (1997) High risk of HIV-related mortality is associated with selenium deficiency. J. Acquir. Immune Defic. Syndr. Hum. Retrovirol., 15, 370-374.

29) The Lipid Research Clinics Coronary Primary Prevention Trial results. II. (1984) The relationship of reduction in incidence of coronary heart disease to cholesterol lowering. JAMA, 251, 365-374.

30) Stamler, J., Wentworth, D. and Neaton, J. D. (1986) Is relationship between serum cholesterol and risk of premature death from coronary heart disease continuous and graded? Findings in 356,222 primary screenees of the Multiple Risk Factor Intervention Trial (MRFIT). JAMA, 256, 2823-2828.

31) Vos, J., de Feyter, P. J., Simoons, M. L., Tijssen, J. G. and Deckers, J. W. (1993) Retardation and arrest of progression or regression of coronary artery disease: a review. Prog. Cardiovasc. Dis., 35, 435-454.

32) Scandinavian Simvastatin Survival Study Group (1995) Baseline serum cholesterol and treatment effect in the Scandinavian Simvastatin Survival Study. Lancet, 345, 1274-1275.

33) Shepherd, J., Cobbe, S. M., Ford, I., Isles, C. G., Lorimer, A. R., MacFarlane, P. W., McKillop, J. H. and Packard, C. J. (1995) Prevention of coronary heart disease with pravastatin in men with hypercholesterolemia. West of Scotland Coronary Prevention Study Group. N. Engl. J. Med., 333, 1301-1307.

34) Kroon, A. A., Aengevaeren, W. R., van der Werf, T. Uijen, G. J., Reiber, J. H., Bruschke, A. V. and 
Stalenhoef, A. F. (1996) LDL-Apheresis Atherosclerosis Regression Study (LAARS). Effect of aggressive versus conventional lipid lowering treatment on coronary atherosclerosis. Circulation, 93, 18261835 .
35) Deagen, J. T., Butler, J. A., Zachara, B. A. and Whanger, P. D. (1993) Determination of the distribution of selenium between glutathione peroxidase, selenoprotein $\mathrm{P}$, and albumin in plasma. Anal. Biochem., 208, 176-181. 